\title{
Association of Microalbuminuria with the Onset of End Organ Damage in Patients with Essential Hypertension
}

\author{
Hermes R.S ${ }^{1}$, Dr.Santhi Silambanan ${ }^{2}$, Dr.M.Emmanuel Bhaskar ${ }^{3}$, \\ Dr. Kalaiselvi V.S. ${ }^{4}$ \\ ${ }^{1}$ Research Scholar , ${ }^{2}$ Professor \& Head, Dept Of Biochemistry Sri Ramachandra Medical College And Research \\ Institute, Sri Ramachandra University, Chennai, India \\ ${ }^{3}$ Professor, Dept Of General Medicine, Sri Ramachandra Medical College And Research Institute, Sri \\ Ramachandra University, Chennai, India \\ ${ }^{4}$ Professor, Dept Of Biochemistry, Sri Balaji Medical College And Hospital, Chromepet, Chennai, India \\ $1 *$ Correspnding Author rs.hermes73@gmail.com
}

\begin{abstract}
:
Background :

Hypertension of long duration especially if not under control leads to damage of retina, kidney, heart and brain. Endothelial dysfunction is considered to be a predominant pathological finding in patients with hypertension. Microalbuminuria, a pathological marker of endothelial dysfunction is frequently elevated in patients with established essential hypertension and is a predictor of a higher risk for cardiovascular disease and renal dysfunction. The presence of microalbuminuria has been shown to correlate with the other cardiovascular risk factors commonly seen in hypertensive patients. This fact indicates that the detection of an increased urinary albumin excretion could be an index of an increased global cardiovascular risk in a given patient. The aim of this study is to evaluate urinary microalbumin in essential hypertensives with and without end organ damage.

Methodology: A total of 255 subjects between the age group of 20-55 years of age, from both sexes who were attending the Hypertensive clinic and Master health check up programme in Sri Ramachandra Medical College were enrolled for the study. They were grouped as three-Group I being controls, Group II hypertensives without complications and Group III hpertensives with end organ damage. After overnight fasting, blood and spot urine samples were collected. All the biochemical parameters were estimated by standard methodologies . Urinary microalbumin was determined by immuno turbidimetric method and creatinine by alkaline picrate method . Albumin Creatinine Ratio (ACR) was also calculated.

Results : Among the hypertensives with end organ damage $71.42 \%$ had microalbuminuria, $23.21 \%$, Left Ventricular Hypertrophy ( LVH ) and $4.44 \%$ had Retinopathy. A strong correlation was observed between Systolic blood pressure (SBP) and microalbumin levels in hypertensives with end organ damage. Highly significant correlation was observed between urinary microalbumin level and creatinine in all the groups. Statistical analysis was done using SPSS Software 19.0.

Discussion: $71.42 \%$ of the hypertensives with end organ damage had microalbuminuria . A highly significant difference was observed in Urinary creatinine and Albumin Creatinine Ratio (ACR ). It is evidenced that renal damage is an early sign of target organ damage in essential hypertensives.

Conclusion: A significant increase in microalbumin levels in essential hypertensives suggests that monitoring the microalbumin levels would be of a great value in assessing the onset of end organ damage.
\end{abstract}

Keywords: Essential hypertension, Microalbuminuria, Cardiovascular risk

\section{Introduction}

Hypertension is a major global chronic non communicable disease. One-quarter of the world's adult population has hypertension, and this is likely to increase to $29 \%$ by 2025 . [ 1 ]. It is currently the leading cause of considerable death and disability world wide and accounted for 9.4 million deaths and 7 per cent of disability adjusted life years (DALYs) in 2010 [2] In a population-based study, in rural area of Maharashtra nearly half of the population was in the pre hypertension stage.( Saoner, Nagpur district) [3]. The prevalence of hypertension in the North Indian population is high and varies between 22 and 29\%.[4 ]. In a cross-sectional study conducted in the rural areas of Andhra Pradesh, India, out of 1624 subjects, between the age group of $18-35$ years, $30.1 \%$ had prehypertension and $7.75 \%$ had hypertension [ 5 ].Hypertension is a multifactorial disorder involving any mechanisms leading to cardiovascular,renal, retinal and neurological complications. It is rather a syndrome of arteriosclerosis and renal involvement leading to sodium retention in addition to elevated blood pressure. This fact indicates that the detection of an increased 
urinary albumin excretion could probably be the best index of an increased global cardiovascular risk in a given patient. Blood pressure control is accompanied by a fall in the concentration of albumin in urine.

\section{Materials \& Methods}

It is a Case-Control Study. Group I consists of healthy individuals with normal blood pressure without any history of any illness or disease. Group II consists of newly diagnosed hypertensives as well as known hypertensives under control without any evidence of end organ damage viz renal, cardiac, retinal changes and serum creatinine level $<1.2 \mathrm{mg} / \mathrm{dl}$. Group III consists of hypertensives with clinical or laboratory evidence of end organ damage viz renal cardiac, retinal changes and serum creatinine level $>1.2 \mathrm{mg} / \mathrm{dl}$. People taking steroids, oral contraceptive pills and fibric acid derivatives and subjects having diabetes, smokers and chronic alcoholics were excluded from the study.

This study was conducted in hypertensive clinic of General Medicine in Sri Ramachandra Medical College.The study has been approved by the Institutional Ethics Committee (IEC-N1/14/JUN/40/35). Out of 255 samples, 138 belonged to Group I , 61 to Group II and 56 to Group III. The fasting blood and spot urine samples were collected from the subjects after informed consent. The anthropometric measurements were recorded. Serum uric acid was estimated by Uricase method, Blood Urea Nitrogen ( BUN ) by Urease method and Creatinine by Alkaline picrate method. The urinary microalbumin was determined by immunoturbidimetric method. ACR was calculated as urinary albumin concentration (mg)/ mmol of creatinine

The obtained data were analysed by ANOVA and post hoc test. SPSS Software Version 19.0 was used. $\mathrm{P}$ value $<0.05$ is considered significant.

Values Are Expressed As Mean \pm SD

\section{Results}

Table 1 represents the age and gender distribution among the 3 groups. There is no difference in the mean age between group II \& III.

Table 1 : Age and Gender distribution among the 3 groups

\begin{tabular}{|l|c|c|c|}
\hline Parameters & Group I $(\mathbf{n}=\mathbf{1 3 8})$ & Group II $(\mathbf{n = 6 1})$ & Group III $(\mathbf{n = 5 6})$ \\
\hline Age & $39 \pm 10$ & $49 \pm 7$ & $49 \pm 6$ \\
\hline Female & 100 & 58 & 50 \\
\hline Male & 38 & 3 & 6 \\
\hline Female : Male ratio & $\mathbf{3 : 1}$ & $\mathbf{1 9 : 1}$ & $\mathbf{8 : 1}$ \\
\hline
\end{tabular}

Table 2 shows the demographic data of 3 groups

Table 2 : Demographic data of the three groups

\begin{tabular}{|l|c|c|c|c|}
\hline Parameters & $\begin{array}{c}\text { Group I } \\
(\mathbf{n = 1 3 8})\end{array}$ & $\begin{array}{c}\text { Group II } \\
(\mathbf{n = 6 1})\end{array}$ & $\begin{array}{c}\text { Group III } \\
(\mathbf{n = 5 6})\end{array}$ & p Value \\
\hline SBP $(\mathrm{mm} \mathrm{Hg})$ & $113 \pm 9$ & $134 \pm 16$ & $137 \pm 18$ & 0.0001 \\
\hline DBP $(\mathrm{mm} \mathrm{Hg})$ & $77 \pm 6$ & $85 \pm 12$ & $87 \pm 10$ & 0.0001 \\
\hline BMI & $23.46 \pm 3.51$ & $24.57 \pm 4.04$ & $25.98 \pm 4.60$ & 0.0001 \\
\hline
\end{tabular}

SBP-Systolic Blood Pressure, DBP-Diastolic Blood Pressure, BMI-Body Mass Index $P$ value $<0.05$ is considered statistically significant.

There is a significant difference in SBP, DBP and BMI between the groups showing that SBP, DBP and BMI increases as the disease progresses.

Post- hoc tests is done to show the significant difference between the groups. The results are expressed below.

Table 3 : Multiple comparative study showing the significant relationship of the demographic data between the 3 groups

\begin{tabular}{|l|c|c|c|}
\hline Parameters & $\begin{array}{c}\text { Group I \& II } \\
(\mathbf{n = 1 3 8 , 6 1})\end{array}$ & $\begin{array}{c}\text { Group II \& III } \\
(\mathbf{n = 6 1 , 5 6})\end{array}$ & $\begin{array}{c}\text { Group I \& III } \\
(\mathbf{n}=\mathbf{1 3 8}, \mathbf{5 6})\end{array}$ \\
\hline SBP mm Hg & 0.00001 & 0.4093 & 0.0001 \\
\hline DBP mm Hg & 0.00001 & 0.3833 & 0.0001 \\
\hline BMI & 0.2456 & 0.1630 & 0.0006 \\
\hline
\end{tabular}

$\mathrm{P}$ value $<0.05$ is considered statistically significant.

There is a highly statistical significant difference in Systolic and Diastolic BP between groups I \& II showing that there is marked increase in BP compared to controls. There is no significant difference when hypertensives were compared those with end organ damage .In case of BMI, there is no significant difference when controls were compared against hypertensives without end organ damage as well as hypertensives with 
that of end organ damage. A statistically significant difference was observed in case of controls when compared with hypertensives with end organ damage. (Table 4 )

Table 4: Biochemical parameters - Renal Profile of the 3 groups

\begin{tabular}{|l|c|c|c|c|}
\hline Parameters & $\begin{array}{c}\text { Group I } \\
(\mathbf{n = 1 3 8})\end{array}$ & $\begin{array}{c}\text { Group II } \\
(\mathbf{n = 6 1})\end{array}$ & $\begin{array}{c}\text { Group III } \\
(\mathbf{n = 5 6})\end{array}$ & p Value \\
\hline BUN (mg/dl ) & $9.73 \pm 3.03$ & $10.03 \pm 2.59$ & $10.79 \pm 2.90$ & 0.075 \\
\hline Serum Creatinine ( mg/dl ) & $0.72 \pm 0.18$ & $0.81 \pm 0.21$ & $0.81 \pm 0.20$ & 0.001 \\
\hline Uric acid (mg/dl ) & $4.82 \pm 1.08$ & $5.08 \pm 1.63$ & $5.37 \pm 1.58$ & 0.032 \\
\hline Urinary microalbumin (mg / ) & $9.34 \pm 5.38$ & $11.45 \pm 4.80$ & $41.36 \pm 2.85$ & $\mathbf{0 . 0 0 0 1}$ \\
\hline Albumin / Creatinine ratio ( mg / mmol ) & $0.99 \pm 0.57$ & $1.20 \pm 0.52$ & $2.37 \pm 1.77$ & $<\mathbf{0 . 0 0 0 1}$ \\
\hline
\end{tabular}

BUN-Blood Urea Nitrogen

$P$ value $<0.05$ is considered statistically significant.

$P$ value $<0.0001$ is considered highly statistically significant.

Statistically significant difference was observed in uric acid and serum creatinine levels. A highly significant difference was observed in urinary microalbumin and Alb/ Creat ratio. There is no statistical significant difference in BUN across the groups.

Table 5: Multiple comparative study showing the significant relationship of the biochemical parameters between the 3 groups

\begin{tabular}{|l|c|c|c|}
\hline Parameters & $\begin{array}{c}\text { Group I \& II } \\
(\mathbf{n = 1 3 8 , 6 1}) \\
\mathbf{p} \text { value }\end{array}$ & $\begin{array}{c}\text { Group II \& III } \\
(\mathbf{n = 6 1 , 5 6}) \\
\mathbf{p} \text { value }\end{array}$ & $\begin{array}{c}\text { Group I\& III } \\
(\mathbf{n = 1 3 8 , 5 6}) \\
\mathbf{p} \text { value }\end{array}$ \\
\hline Serum Creatinine $(\mathrm{mg} / \mathrm{dl})$ & $\mathbf{0 . 0 4 0 7}$ & 0.6508 & $\mathbf{0 . 0 0 1 8}$ \\
\hline Uric acid (mg/ dl ) & 0.4646 & 0.4689 & $\mathbf{0 . 0 2 9 6}$ \\
\hline Urinary microalbumin (mg / l) & 0.8024 & $\mathbf{0 . 0 0 0 1}$ & $<\mathbf{0 . 0 0 0 1}$ \\
\hline Albumin/Creatinine ratio mg/mmol) & 0.382 & $\mathbf{0 . 0 0 0 1}$ & $<\mathbf{0 . 0 0 0 1}$ \\
\hline
\end{tabular}

$P$ value $<0.05$ is considered statistically significant.

$\mathrm{P}$ value $<0.0001$ is considered highly statistically significant.

Considering the renal profile, statistical difference was observed in uric acid levels between group I \& III Serum creatinine was found to be statistically significant between group I \& II and group I \& III. Urinary microalbumin and Alb/ Creat ratio showed highly statistical difference between group II \& III and group I \& III.

The microalbumin levels of individual groups were compared with the other variables to find out the correlation between them and the results are expressed as given in the following table.(Table 6 )

Table 6 : Pearson correlation of Urinary microalbumin and other variables

\begin{tabular}{|l|c|c|c|c|c|c|}
\hline $\begin{array}{l}\text { Correlation of Urinary Microalbumin with } \\
\text { other parameters }\end{array}$ & \multicolumn{2}{|c|}{ Group I } & \multicolumn{2}{c|}{ Group II } & \multicolumn{3}{c|}{ Group III } \\
\cline { 2 - 7 } & r value & P value & r value & P value & r value & P value \\
\hline Microalbumin with SBP & -0.085 & 0.321 & 0.169 & 0.192 & 0.289 & 0.031 \\
\hline Microalbumin with DBP & 0.010 & 0.907 & -0.036 & 0.784 & 0.165 & 0.224 \\
\hline Microalbumin with BMI & 0.041 & 0.632 & 0.023 & 0.861 & 0.023 & 0.866 \\
\hline Microalbumin with BUN & 0.214 & 0.012 & 0.302 & 0.018 & 0.164 & 0.226 \\
\hline Microalbumin with Uric acid & -0.010 & 0.905 & 0.034 & 0.794 & -0.018 & 0.898 \\
\hline Microalbumin with serum creatinine & 0.131 & 0.125 & 0.073 & 0.576 & -0.084 & 0.537 \\
\hline $\begin{array}{l}\text { Microalbumin with Albumin /Creatinine } \\
\text { Ratio }\end{array}$ & 0.5235 & $<0.0001$ & 0.216 & 0.094 & 0.83 & $<0.0001$ \\
\hline
\end{tabular}

$\mathrm{P}$ value $<0.05$ is considered statistically significant.

$P$ value $<0.0001$ is considered highly statistically significant.

In group I and group II correlation was observed in microalbumin levels and BUN levels . A strong correlation was observed between Systolic blood pressure and microalbumin levels in hypertensives with end organ damage (Group III) . Microalbumin and urea levels showed a positive correlation in hypertensives without end organ damage. Highly significant correlation was observed between urinary microalbumin level in all the groups.

\section{Discussion}

Albumin is a small and globular protein possessing negative charge at blood $\mathrm{pH}$ of 7.4.These negative charges in the albumin repel against the positive charges of the Glomerular Basement membrane thus 
decreasing the filtration. In patients with microalbuminuria due to the loss of negative charges in Glomerular Basement Membrane the filtration of albumin is increased.

Normal urine contains up to $30 \mathrm{mg} / \mathrm{g}$ creatinine, or $30 \mathrm{mg}$ albumin/L urine. [ 6 ] Increased urinary albumin excretion (UAE) has been suggested as a useful marker of end organ damage ( EOD) as well as increased risk of cardiovascular disorders [ 7 ] .

In non-diabetic hypertensives the pathogenic mechanisms underlying increased UAE has not been elucidated. At present two mechanisms are found to play a role. $[8,9]$

One mechanism suggests that there is an increased glomerular basement membrane permeability leading to elevated BP in the glomeruli. In glomeruli, blood enters through afferent arteriole and exits through efferent arteriole ,hence leakage of albumin in urine indicates damage to the blood vessel. The same type of damage can be present in other parts of the body[ 10 ]. Other mechanism suggests that this could also be due to early endothelial dysfunction of the blood vessels.[11,12 ]

The association between Microalbumniuria (MA ) and Hypertension has been studied as early as in 1974 by Parving et al [13]. MA has a major impact on cardio vascular risk [ 14]. It has become a prognostic marker for cardiovascular disorders. Thus several mechanisms like increased filtration, abnormalities of the glomerular basement membrane and endothelial dysfunction are responsible for an increase in trans glomerular passage of albumin in patients with essential hypertension [ 15 ]. Microalbuminuria is considered to be a marker of endothelial dysfunction and end organ damage.[ 16,17].

The prevalence of MA was found to be 33.3\% according to Ravjit Kaur Sabharwal et al [18 ] in agreement with the study of Rosa TT, Cerasola G and Agrawal B [19,20,21 ] According to our study individuals in Group III the prevalence of microalbumiuria is $(71.42 \%)$, higher than the findings obtained by the other studies [ 22,23,24 ]. MAGIC Study ( Microalbumiuria - A Genoa Investigation on Complications ) conducted by Roberto Pontremoli et al has indicated reported the prevalence of MA in essential hypertension as $6.67 \%$.. [25].

Several studies suggest that prevalence of MA in HT varies from 7 to $40 \%$ depending upon the age and ethnic group $26,27,28,29,30$ ]. However the prevalence was found to be $63 \%$ out of 100 hypertensives in a study by Sharan Badiger et al in 2011[ 31 ] Microalbuminuria represents the generalized vascular endothelial dysfunction thus contributing to increased cardiovascular disease risk [ 32 ]. Microalbumin starts increasing in hypertensives even before they go in for end organ damage.

In obesity there occurs an alteration in the vascular endothelial structure and function. This is found to predispose to peripheral and coronary artery disease . According to the Framingham Cohort study obesity accounts for $78 \%$ \& $65 \%$ of Essential Hypertension in men and women. There is statistically significant difference in weight ( $p$ value 0.0001 ) and BMI ( $p$ value 0.0006 ) as the disease advances to hypertension with end organ damage. But there is no statistical difference between normal individuals when compared against hypertensives with no evidence of end organ damage Several epidemiological studies show that MA is an independent predictor of cardiovascular morbidity and mortality in patients with essential hypertension [ 33,

34 ]. Serum creatinine urea, uric acid (although in normal range ) were significantly higher in hypertensives compared to the control group in a study conducted by Jalal et al in 2001[ 35 ] . In accordance with this study we observed a statistical difference in BUN, uric acid levels when hypertensives with end organ damage were compared against controls. Serum creatinine was found to be statistically significant between the groups showing that there is continuous increase in creatinine with the progression of the disease.

The spot urine Albumin Creatinine (A:C) ratio is a better estimate of 24 hrs Albumin Excretion Rate (AER) in urine $[36,37,38]$. Highly statistically significant difference $(\mathrm{p}<0.0001)$ was observed in Albumin Creatinine ratio as the disease progresses from hypertension to hypertension with end organ damage in our study. As per the ADA 2001 recommendations [39], A: C ratio can be used for urinary albumin estimation to detect microalbuminuria.

There is no statistical significant increase in BUN across the groups probably due to

(i) Easily dialysable property of urea as compared to creatinine

(ii) Decreased intake of protein

(iii) Decreased reabsorption of urea as the disease condition progresses.

However BUN showed a significant correlation with microalbumin in group I and group II $(\mathrm{p}=0.012$ and $\mathrm{p}=$ $0.018)$ in a study conducted in the Egyptian population respectively as supported by the above study $(\mathrm{p}<0.001)$ [40 ]. There is correlation between SBP and microalbumin only in hypertensives with end organ damage indicating that SBP increases significantly as the hypertensives reach the stage of getting end organ damage. BUN is correlated with microalbumin in group I \& II and not in group III indicating that elevation of BUN levels onsets in hypertensives even before they go in for end organ damage. Microalbumin is correlated with urine creatinine indicating that microalbumin starts increasing in control group itself and remains elevated in hypertensives without evidence of end organ damage as well as with evidence of end organ damage. The 
systemic capillary permeability is altered in hypertension due to acceleration of hyperfiltration, transcapillary macromolecular transport causing damage to endothelial cell membrane passage [ 41].

\section{Conclusion}

Essential hypertension is asymptomatic contributing to about 95\% of hypertension. Essential hypertensives are unaware of the end organ damage. Various studies have suggested detection of microalbuminuria and determination of $\mathrm{A}: \mathrm{C}$ ratio would provide an index of EOD in essential hypertensives. There has recently been considerable interest in the quantitative measurement of microalbumin to detect subtle effects of hypertension on the kidney.Considering the renal profile statistical difference, microalbumin is associated with endothelial dysfunction which is the hallmark of hypertension. Hence monitoring the microalbumin levels , A:C ratio in newly diagnosed as well as known hypetensives under control would help to assess the onset of end organ damage.

\section{List of abbreviations}

A: $C$

Albumin Creatinine ratio

$B M I$

$B U N$

Body Mass Index

Blood Urea Nitrogen

$D B P$

Diastolic Blood Pressure

MA

Microalbuminuria

$S B P$

Systolic Blood Pressure

Declarations

Competing interests

The authors declare that they have no competing interest.

Funding:

No funding agencies are involved in this study

\section{Acknowledgments}

This work was supported by Founder-Chancellor Research Fellowship, Sri Ramachandra University Chennai, India

Authors' Affiliations

(1) and (2)

Dept of Biochemistry Sri Ramachandra Medical College and Research Institute, Sri Ramachandra University, Chennai, India

(3)

Dept of General Medicine, Sri Ramachandra Medical College and Research Institute, Sri Ramachandra University, Chennai, India

(4)

Dept of Biochemistry, Sri Balaji Medical College and Hospital, Chennai, India

\section{References}

[1]. Bharati V. Mittal, MD, and Ajay K. Singh, Hypertension in the Developing World: Challenges and Opportunities, Am J Kidney Dis 55:590-598. 2010

[2]. Lim SS, Vos T, Flaxman AD, Danaei G, Shibuya K, Adair-Rohani H, et al. A comparative risk assessment of burden of disease and injury attributable to 67 risk factors and risk factor clusters in 21 regions, 1990-2010: a systematic analysis for the Global Burden of Disease Study 2010. Lancet 2013; $380: 2224-60$.

[3]. Bhardwaj Sumit D, Sinha Umesh, Shewte Mamta K, Khadse Jyoti R, Bhatkule Prakash R, Prevalence, awareness, treatment and control of hypertension among the people above 15 years in rural area nagpur maharashtra - a cross sectional study National Journal of Community Medicine Vol 3 Issue 2 April-June 2012

[4]. A Poduri, S Kumari, S Jain and M Khullar A case-control study of the association between the MTHFR gene and essential hypertension in Asian Indians Journal of Human Hypertension (2009) 23, 140-142; 
[5]. S Srinivas , K Satyavaraprasad, Ramdas , CPRS Krishna , Tajuddin , R.Prabhakar Rao Prevalence of Prehypertension in Adult population of Rural Andhra Pradesh Asian Journal of Biomedical and Pharmaceutical Sciences; 3(23) 2013, 45-48

[6]. Sacks D. B. - Urinary albumin excretion. In: Tietz textbook of clinical chemistry and molecular diagnostics. 4th ed. Burtis CA, Ashwood ER, Bruns DE. New Delhi: Saunders Elsevier. p. 886-888, 2006.

[7]. Viberti G., Thomas S. — Should we screen for microalbuminuria in essential hypertension? Am J Kidney Dis. 34:1139-1141, 1999.

[8]. Bianchi S., Bigazzi R., Campese V. M. - Microalbuminuria in essential hypertension: significance, pathophysiology, and therapeutic implications. Am J Kidney Dis. 34:973-995, 1999.

[9]. Pedrinelli R. - Microalbuminuria in hypertension. Nephron. 73:499-505, 1996.

[10]. Pontremoli R., Sofia A., Ravera M., Nicolella C., Viazzi F., Tirotta A., et al. - Prevalence and clinical correlates of microalbuminuria in essential hypertension: the MAGIC study. Hypertension.30:1135-1143, 1997.

[11]. Pedrinelli R., et al. — Microalbuminuria and endothelial dysfunction in essential hypertension.Lancet. 344:14-18, 1994.

[12]. Pontremoli R., et al. — Prevalence of micro- and macroalbuminuria and their relationship with other cardiovascular risk factors in essential hypertension.Nephrol Dial Transplant. 10 (Suppl 6): S6-9, 1995.

[13]. Parving HH, Jensen HE, Mogensen CE, Evrin PE. Increased urinary albumin excretion rate in benign essential hypertension. Lancet 1974;: 1190-92.

[14]. Zuccala A, Fiorenza S, Rapana R, Santoro A. Hypertension,atherosclerosis and kidney. G Ital Nefrol 2005; 22 Suppl 31:S9-14.

[15]. Redon J, Pascual JM. Development of microalbuminuria in essential hypertension. Curr Hypertens Rep 2006; 8(2): 171-7

[16]. Pedrinelli R, Dell'Omo G, Di Bello V,Pontremoli R and Mariani M. Microalbuminuria, an integrated marker of cardiovascular risk in essential hypertension. J Hum Hypertens.2002;16:79-89.

[17]. Dick de Zeeuw, Hans-Henrik Parving and Robert $\mathrm{H}$ Henning. Microalbuminuria as an early marker for cardiovascular disease.JASN. 2006;17(8):2100-2105.

[18]. Ravjit Kaur Sabharwal, Parduman Singh, M M Arora, B L Somani and Vivek Ambade.in Incidence of microalbuminuria hypertensive patients, Indian Journal of Clinical Biochemistry, 2008 / 23 (1) 71-75

[19]. Rosa TT, Palatini P. Clinical value of microalbuminuria in hypertension. J Hypertens 2000; 18(6): 645-54

[20]. Cottone S, Mule G. Microalbuminuria, renaldysfunction \& cardiovascular complications in essential hypertension. J Hypertens $1996 ; 14: 915-20$

[21]. Agrawal B, Berger A, Wolf K, Luft FC. Microalbuminuria screening by reagent strip predicts cardiovascular risk in hypertension. J Hypertens 1996; 14:223-28.

[22]. Hornych A, Marre M, Mimran A, Chaignon M, Asmar R,Fauvel JP. Microalbuminuria in arterial hypertension.Measurement, variables, interpretation, recommendations.Arch Mal Coeur Vaiss 2000; 93(11): 1304-8.

[23]. Mimran A, Ribstein J, Du Cailar G. Microalbuminuria in essential hypertension. Current opinion in nephrology and hypertension 1999; 8(3): 359-63.

[24]. Col M, Ocaktan E, Ozdemir O, Yalcin A, Tuncbilek A Microalbuminuria: prevalence in hypertensives and diabetics.Acta Med Austriaca $2004 ; 31(1): 23-9$.

[25]. Pontremoli R, Sofia A, Ravera M. Prevalence and clinical correlates of microalbuminuria in essential hypertension: the MAGIC Study. Microalbuminuria: A Genoa Investigation on Complications. Hypertension 1997; 30(5): 1135-43.

[26]. Redon J, Pascual JM, Miralles A, Sanz C, Gutierrez M, Ros MJ et al: Microalbuminuria in essential arterial hypertension. Med Clin (Barc) 1991; 96:525 - 9 .

[27]. Bianchi S, Bigazzi R, Campese VM: Microalbuminuria in essential hypertension: significance, pathophysiology, and therapeutic implications. Am J Kidney Dis 1999; 34: 973 - 95.71

[28]. Tomura S, Kawada K, Saito K, Lin YL, Endou K, Hirano C et al: Prevalence of microalbuminuria and relationship to risk of cardiovascular disease in the Japanese population. Am J Nephrol 1999; 19:13-20.

[29]. Ljungman S: Microalbuminuria in essential hypertension. Am J Hypertens 1990; 3: 956 - 60

[30]. Summerson JH, Bell RA, Konen JC: Racial differences in the prevalence of microalbuminuria in hypertension. Am J kidney Dis 1995; $26: 577-79$

[31]. Sharan Badiger, Sandeep HM , Satish C Talikoti , Biradar MS A Study of Microalbuminuria and Target Organ Damage in Patients with EssentialHypertension , Int J Biol Med Res. 2012; 3(1): 1351-1355

[32]. Sumit Agarwal, M Venkataraya Prabu, Arun S ,Veena J, Pinto, Gopalakrishna Bhat K, Deepti Mangala. Correlation of microalbuminuria with cardiovascular morbidity in essential hypertension. International Journal of Clinical Cases and Investigations, 2013,Volume 5,( Issue 6 ), 7:76, $1^{\text {st }}$ July 2014

[33]. Bianchi S, Bigazzi R, Baldari G, Campese VM.Microalbuminuria in patients with essential hypertension.Effect of several anti hypertensive drugs. Am J Med 1992; 93 : 525-28. Copyright (C) 2001 by The Indian Society of Nephrology

[34]. Yudkin JS, Forrest RD, Jackson CA. Microalbuminuria as a predictor of vascular disease in non-diabetic subjects. Lancet 1988; 2 : $530-33$.

[35]. S Jalal, FA Sofi , MS Alai, MA Sidiqqi, MA Bhat, KA Khan, VM Jan, NA Lone, HA Rather, Prevalence of microalbuminuria in essential hypertension: A study of patients with mild to moderate hypertension. Indian Journal of Nephrology Indian J Nephrol 2001;11: 6-11

[36]. Rodby RA, Rohde RD, Sharon Z, Pohl MA, Bain RP, Lewis EJ. The urine protein to creatinine ratio as a predictor of 24hour urine protein excretion in type 1 diabetic patients with nephropathy. The Collaborative Study Group. Am J Kidney Dis 1995; 26(6): 9049.

[37]. Eshoj O, Feldt-Rasmussen B, Larsen ML, Mogensen EF. Comparison of overnight, morning and 24-hour urine collections in the assessment of diabetic microalbuminuria. Diabet Med 1987; 4(6): 531-3.

[38]. Goldschmid MG, Domin WS, Ziemer DC, Gallina DL, Phillips LS. Diabetes in urban African-Americans. II. High prevalence of microalbuminuria and nephropathy in African-Americans with diabetes. Diabetes Care 1995; 18(7): 955-61

[39]. ADA Standards of medical care for patients with diabetes mellitus: Diabetic nephropathy. Diabet Care 2001; 24 Suppl I: S33-S43

[40]. Mahmoud AH, and Taha HM,Study of the Relationship between Abdominal Obesity and Micro-Albuminuria in Elderly, Journal of Obesity and Overweight,Volume 1 | Issue 2: 1-6.

[41]. Roberto Pedrinelli,Giuseppe Penno,Giulia Dell'Omo,Simona Bandinelli,Davide Giorgi, Vitantonio Di Bello ,” Microalbuminuria and transcapillary albumin leakage in essential hypertension", Hypertension. 1999; 34, pp.491-495 